\title{
A benign hydrothermal synthesis of nanopencils-like zinc oxide nanoflowers
}

\author{
S. A. Akhoon $\cdot$ S. Rubab $\cdot$ M. A. Shah
}

Received: 19 August 2014/Accepted: 23 October 2014/Published online: 1 November 2014

(C) The Author(s) 2014. This article is published with open access at Springerlink.com

\begin{abstract}
Synthesis of zinc oxide $(\mathrm{ZnO})$ nanoflowers and nanopencils is normally carried out with the help of structure-directing chemicals and templates. Besides releasing environmentally toxic substances, the use of these chemicals restricts the practical applications of nanostructures. In this paper, we report a typical template-free and environmentally benign synthesis of $\mathrm{ZnO}$ nanoflowers with nanopencils-like petals through a facile hydrothermal method. The as-synthesized $\mathrm{ZnO}$ nanoflowers were characterized using X-ray diffraction, field emission scanning electron microscopy, tunneling electron microscopy (TEM), high resolution TEM, and energy-dispersive X-ray spectroscopy techniques. The results reveal high quality and impurity-free hexagonal wurtzite phase $\mathrm{ZnO}$ nanoflowers of nanopencils-like petals having a length of $100-150 \mathrm{~nm}$ and a diameter of $45-60 \mathrm{~nm}$.
\end{abstract}

Keywords Hydrothermal - Environmentally benign .

Nanoflower $\cdot$ Nanopencils $\cdot$ Economical

\section{Introduction}

Nanocrystalline metal oxides play a very important role in material science due to their tunable morphology and wide applications in optoelectronics, energy conversions,

\footnotetext{
S. A. Akhoon $(\bowtie) \cdot$ S. Rubab $\cdot$ M. A. Shah $(\bowtie)$

National Institute of Technology,

Srinagar 190006, Jammu and Kashmir, India

e-mail: akhoon.shabir@yahoo.com

M. A. Shah

e-mail: shah@nitsri.net

S. Rubab

e-mail: drseeminrubab@gmail.com
}

microelectronics, optics, and biology [1, 2]. Among the most reported metal oxides, zinc oxide $(\mathrm{ZnO})$ has been mostly characterized as a photonic material for its several applications, for example for solar cells [3]. $\mathrm{ZnO}$ is a significant technological semiconductor material with a wide band gap of $3.37 \mathrm{eV}$ and a large exciton binding energy of $60 \mathrm{meV}$. The morphological diversity of $\mathrm{ZnO}$ in the nanoregime has made it a promising candidate for high performance devices in the field of nanotechnology [4]. The properties of $\mathrm{ZnO}$ nanostructures have been found to strongly depend on their morphology [5]. Its morphology usually includes nanowires, nanorods, nanobelts, nanorings, nanosheets, nanoflakes, nanoflowers, and nanopencils [6-8]. Among these nanostructures, current and future possible applications of $\mathrm{ZnO}$ nanoflowers, with petals of nanorods, nanowires, and nanopencils, etc., for optoelectronic devices and solar cells have caused a great interest throughout the scientific community [9]. These structures have been synthesized through both the physical and chemical methods. However, physical methods need expensive equipments, high temperatures, and complex procedures which restrict further development in actual applications.

$\mathrm{ZnO}$ nanopencils and nanoflowers through chemical route of hydrothermal synthesis have been reported by many researchers in the past [5, 9-13]. All these synthesis procedures include decomposition of different precursor salts with the addition of catalysts and different environmentally malignant chemicals, which are toxic and not easily degraded in the environment [14]. Therefore, the hazardous impact of these toxic chemicals provides a motivation and a desire to synthesize nanostructures without the use of environmentally malignant chemicals and in particular, $\mathrm{ZnO}$ nanoflower structures, considering its use in energy and environmental applications. 
In our earlier studies, we were able to obtain $\mathrm{ZnO}$ nanostructures through the facile and environmentally benign process at very moderate temperatures by varying time and temperature of the reaction $[4,14,15]$. Impressed by the results, we were prompted to look into more conditions so as to synthesize more novel structures and as such, in this paper we report the synthesis of $\mathrm{ZnO}$ nanoflower, consisting of nanopencils-like petals through an environmentally benign hydrothermal method. This synthesis method besides being organic free is economical, fast, and free of pollution, which makes it suitable for possible large scale production and green synthesis of different metal oxide nanostructures.

\section{Experimental}

\section{Materials}

Zinc powder (Ranbaxy Chemicals, particle size $>5 \mu \mathrm{m}$ ), was used without any purification or any treatment and distilled water. For the synthesis of $\mathrm{ZnO}$ nanoflowers, a Teflon lined stainless steel cylindrical chamber $(60 \mathrm{ml})$ has been used.

\section{Synthesis}

In the typical synthesis of $\mathrm{ZnO}$ nanoflowers, consisting of nanopencils, $10 \mathrm{mg}$ of zinc powder was taken with $50 \mathrm{ml}$ of distilled water. Both reagents were dissolved in a stainless steel chamber with $60 \mathrm{ml}$ capacity. The stainless steel chamber was then tightly fixed and transferred to an oven at $210^{\circ} \mathrm{C}$. The reaction was allowed to carry on for $16 \mathrm{~h}$. The system was switched off after the desired time and was allowed to cool down under normal conditions and was left as such for $8 \mathrm{~h}$. The products were retrieved and centrifuged twice before drying in open air conditions at a temperature of $80^{\circ} \mathrm{C}$. The final products were characterized without any further treatment.

\section{Characterization}

The products were characterized for their phase, purity, and structure by employing XRD and EDX. The XRD patterns of the powdered products were plotted using a $\mathrm{CuK} \alpha$ radiation $(\lambda=0.15418 \mathrm{~nm})$ from a Siemens D 5005 diffractometer. The crystallite size of the particles was calculated using the Scherer equation for maximum intensity (101) reflection plane. The morphology and particle size were carried out using high resolution FESEM (FEI NOVA NANOSEM-600) coupled with energy-dispersive X-ray spectrometer and Transmission electron microscopy (TEM) (JEM-2010HR, Jeol Japan). The lattice fringe width and possible preferred orientation were observed by HRTEM images, which were further studied for structural characteristics.

\section{Results and discussions}

X-Ray diffraction

The X-ray diffraction (XRD) analysis was employed to determine the phase structure and purity of the as-synthesized $\mathrm{ZnO}$ powder. The XRD pattern of the as-synthesized $\mathrm{ZnO}$ is shown in Fig. 1. The XRD data analysis clearly reveals the crystalline nature of $\mathrm{ZnO}$ nanopencils and closely matches with the standard diffraction pattern of $\mathrm{ZnO}$ and International Centre for Diffraction Data, Joint Committee on Powder Diffraction Standards (JCPDS) 36-1451. The observed XRD profile was closely analyzed and compared with that of JCPDS data for the hexagonal $\mathrm{ZnO}$ as shown in Table 1 . The diffraction peaks and relative intensity matched very well with hexagonal wurtzite phase without having any additional peaks, except for the peaks which are characteristic of $\mathrm{ZnO}$. This suggests that the synthesis of $\mathrm{ZnO}$ nanopencils via this facile hydrothermal route is of high quality and impurity free. Further, the sharp peaks in the XRD pattern suggest that the $\mathrm{ZnO}$ nanopencils are highly crystalline. The peaks at $2 \theta=31.77^{\circ}, 34.47^{\circ}, 36.23^{\circ}, 47.53^{\circ}, 56.62^{\circ}, 62.90^{\circ}$, $66.40^{\circ}, 67.90^{\circ}, 69.06^{\circ}$, and $72.50^{\circ}$ were assigned to (100), (002), (101), (102), (110), (103), (200), (112), (201), and (004) reflection planes of hexagonal wurtzite $\mathrm{ZnO}$ (space group: $\mathrm{P}_{3} \mathrm{mc}$ ), having lattice constants of $a=0.3249 \mathrm{~nm}$, $c=0.5206 \mathrm{~nm} \mathrm{[4].}$

\section{Formation mechanism}

During the hydrothermal synthesis process, a critical temperature/pressure breaks down the $\mathrm{ZnO}$ crystals to nanosize in the mixture and as the evaporation takes place, both the concentration and temperature change at the surface. This causes an instability which drives the convection after the liquid evaporates at a certain critical rate [16]. Now if one isotropic phase (liquid, like a homogeneous mixture of $\mathrm{ZnO}$ particles and distilled water) is surrounded by another phase (vapor) and the interface between the two phases is in equilibrium, then, the interface between the liquid phase and the vapor phase ceases to exist and hence the two phases become identical [17].Thus, a critical temperature and a critical pressure should be sufficient for the growth of nanostructures, as observed in our earlier studies [4, 14, $15]$.

The formation mechanism of $\mathrm{ZnO}$ nanopencils can be explained on the basis of reaction between zinc powder and 
Fig. 1 EDX and XRD spectra (inset) of $\mathrm{ZnO}$ nanopencils

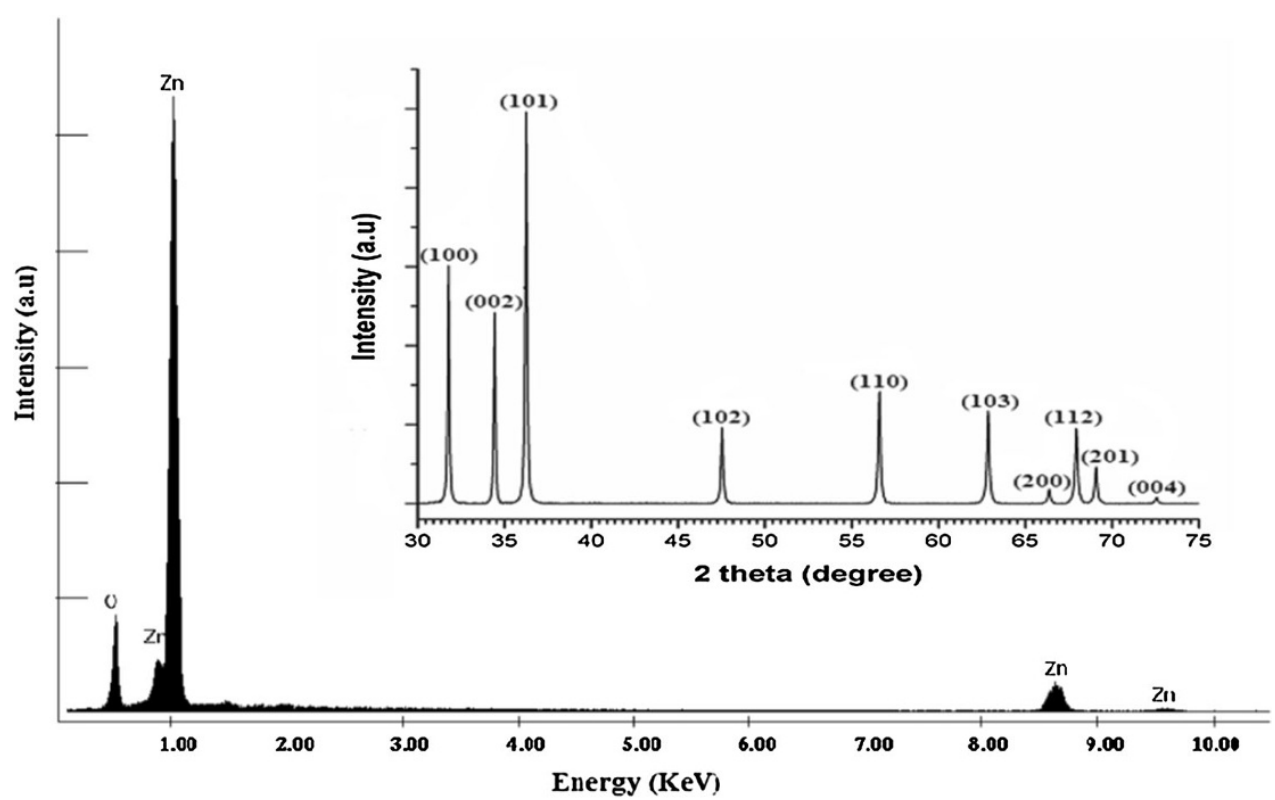

Table 1 Comparison of observed XRD profile with that of the JCPDS profile

\begin{tabular}{lllcc}
\hline $\begin{array}{l}\text { Reflection } \\
\text { planes } \\
(\mathrm{hkl})\end{array}$ & $\begin{array}{l}2 \theta\left(^{\circ}\right) \\
\text { from } \\
\text { JCPDS }\end{array}$ & $\begin{array}{l}2 \theta\left(^{\circ}\right) \\
\text { observed }\end{array}$ & $\begin{array}{l}\text { Relative } \\
\text { intensity from } \\
\text { JCPDS }\end{array}$ & $\begin{array}{l}\text { Relative } \\
\text { intensity } \\
\text { observed }\end{array}$ \\
\hline$(100)$ & 31.728 & 31.77 & 57.85 & 60.63 \\
$(002)$ & 34.400 & 34.47 & 44.24 & 48.51 \\
$(101)$ & 36.212 & 36.23 & 100 & 100 \\
$(102)$ & 47.494 & 47.53 & 22.92 & 19.51 \\
$(110)$ & 56.519 & 56.62 & 32.43 & 28.55 \\
$(103)$ & 62.803 & 62.90 & 27.62 & 23.55 \\
$(200)$ & 66.283 & 66.40 & 4.40 & 4.04 \\
$(112)$ & 67.866 & 67.90 & 24.32 & 19.05 \\
$(201)$ & 68.992 & 69.06 & 11.41 & 9.67 \\
$(004)$ & 72.516 & 72.50 & 1.90 & 1.487 \\
\hline
\end{tabular}

(a)

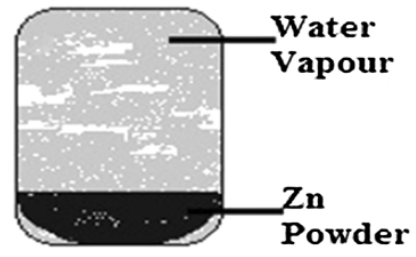

(b)

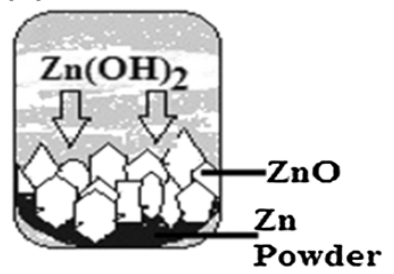

Fig. 2 Illustration of $\mathrm{ZnO}$ nanopencil growth. a Initially $\mathrm{Zn}$ particles and water vapour co-exist. b $\mathrm{Zn}(\mathrm{OH})_{2}$ region formed, which decomposes to $\mathrm{ZnO}$

water under high pressure at $210{ }^{\circ} \mathrm{C}$. It formed a zinc hydroxide $\left[\mathrm{Zn}(\mathrm{OH})_{2}\right]$ layer with hydroxide ions onto the surface of the zinc foil [14] as illustrated in Fig. 2.
The $\mathrm{Zn}(\mathrm{OH})_{2}$ resulted in the formation of $\mathrm{ZnO}$ crystals under the simple reaction as

$\mathrm{Zn}(\mathrm{OH})_{2} \rightarrow \mathrm{ZnO}+\mathrm{H}_{2} \mathrm{O}$

As zinc hydroxide is more soluble than zinc, more and more surface layers of zinc were exposed to the hydroxide ions. This resulted in a continuous formation of zinc hydroxide. Under these ambient conditions, the $\mathrm{ZnO}$ crystals, during the growth process resulted in the formation of $\mathrm{ZnO}$ nanoflowers from $\mathrm{ZnO}$ nanopencils in a self assembling process.

\section{Energy-dispersive X-ray}

Energy-dispersive X-ray analysis (EDX) was carried out to investigate the purity and the chemical composition of the assynthesized $\mathrm{ZnO}$ nanopencils. The EDX spectrum is shown in Fig. 1. The energy peak at $0.525 \mathrm{keV}$ corresponds to oxygen ( $\mathrm{K}$ line) and peaks at $0.906,1.102 \mathrm{keV}$ corresponds to zinc (L line), while as 8.630 and $9.578 \mathrm{keV}$ correspond to zinc ( $\mathrm{K}$ line). From the EDX analysis, it is clear that the chemical composition is purely zinc ( $\mathrm{Zn})$ and oxygen $(\mathrm{O})$, with no other impurity contents. Thus, EDX analysis also supports the high purity of the sample and is in agreement with the XRD analysis, which also confirmed the same.

\section{Electron microscopy}

Scanning electron microscopy

FESEM micrographs of the as-synthesized $\mathrm{ZnO}$ powder were employed to study the surface morphology and 

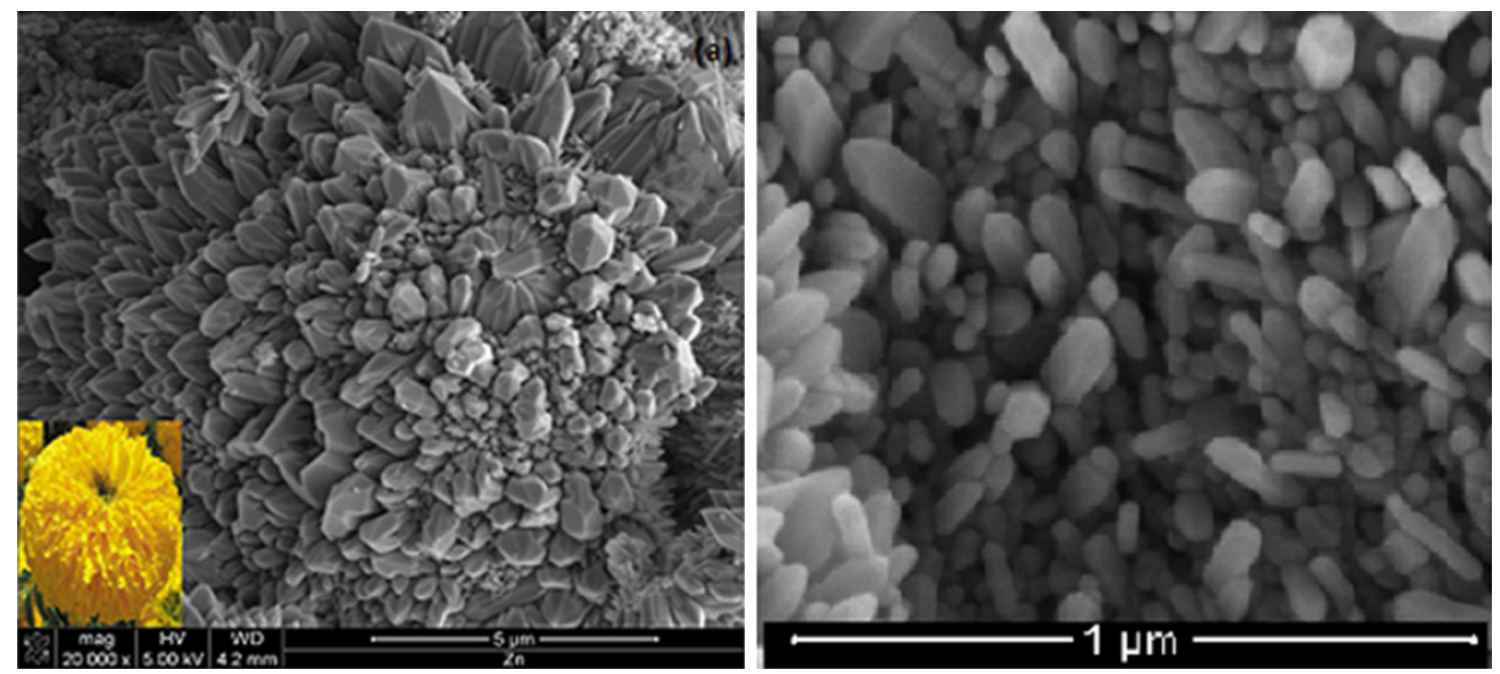

Fig. 3 Low and high resolution FESEM images of $\mathrm{ZnO}$ nanoflower and nanopencils
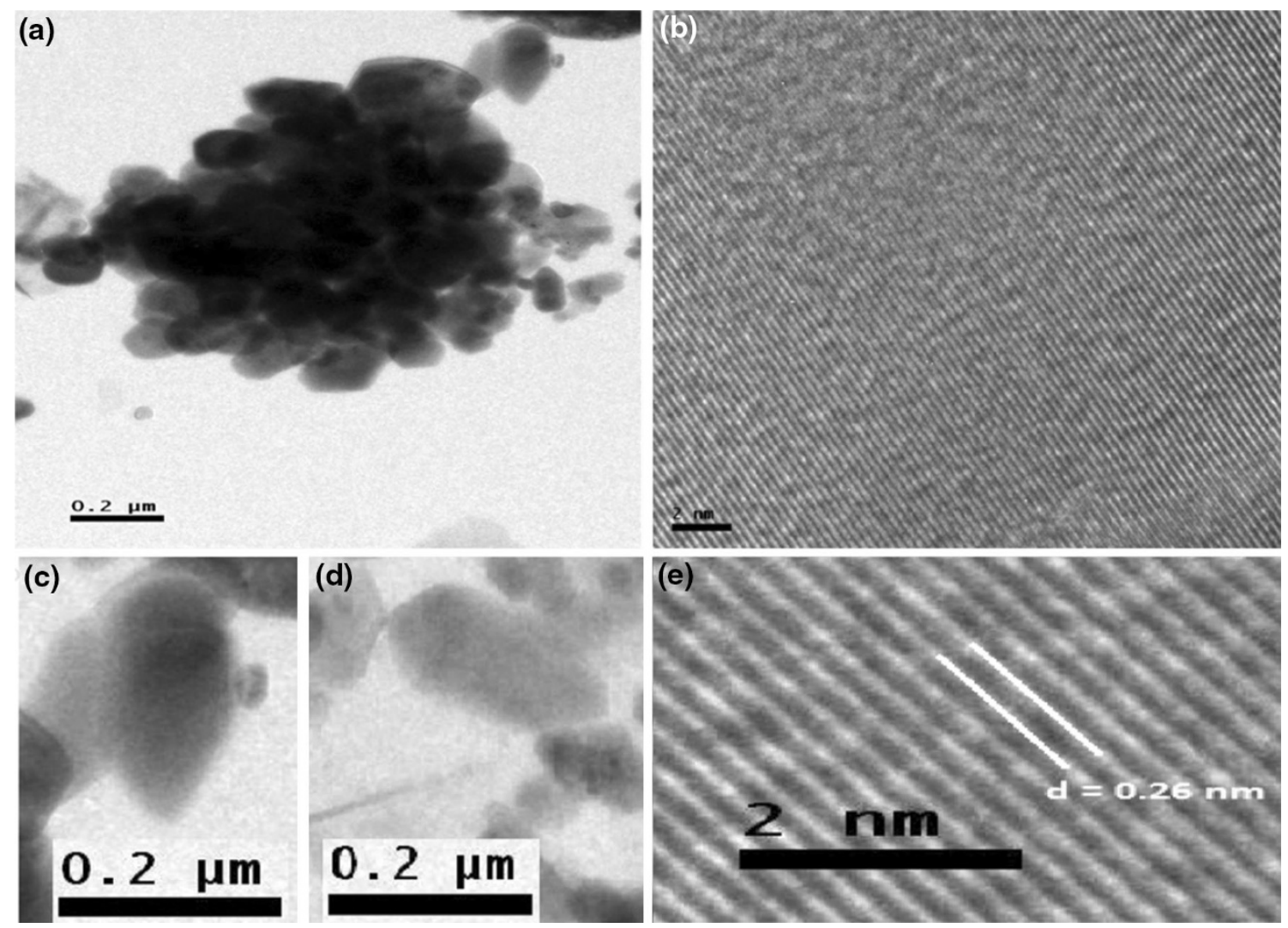

Fig. 4 a TEM and b HRTEM image of synthesized nanopencils-like ZnO flower. $\mathbf{c}-\mathbf{e}$ The magnified TEM and HRTEM images of $\mathbf{a}$ and $\mathbf{b}$

particle size. The FESEM images are reproduced in Fig. 3. A cursory look at the images clearly reveals the flower-like morphology with pencil-shaped rod-like petals, with smooth surfaces and pointed tips. However, as observed from Fig. 3b, the $\mathrm{ZnO}$ nanopencils have a wide size distribution. The length of the nanopencils is $100-150 \mathrm{~nm}$, with a diameter falling within a range of 45-60 nm, while least of these are having a diameter of 80-90 $\mathrm{nm}$. It is also evident that the $\mathrm{ZnO}$ nanopencils are having a hexagonal structure. While Pol and co-workers and other works in the past reported the pencil-shaped $\mathrm{ZnO}$ nanorods at $700{ }^{\circ} \mathrm{C}$ for $24 \mathrm{~h}$ or greater [18], we observed the pencil-like $\mathrm{ZnO}$ 
nanorods together with flower-like morphology at $210{ }^{\circ} \mathrm{C}$ for $16 \mathrm{~h}$.

\section{Transmission electron microscopy}

To further study the structural and morphological characteristics, the as-synthesized $\mathrm{ZnO}$ powder was characterized using the TEM and HRTEM techniques, the results of which are shown in Fig. 4. In Fig. 4a, the TEM images clearly reveal the hexagonal structure with a diameter in the range of 50-90 $\mathrm{nm}$ of $\mathrm{ZnO}$ nanoflower with nanopencils-like petals confirming the FESEM results. Figure 4c, d are the magnified images of Fig. 4a. These images clearly demonstrate the nanopencils-like structures having pointed tips. From the HRTEM images as shown in Fig. 4b, e, the lattice fringes can be clearly observed. The interval distance of $0.26 \mathrm{~nm}$ between adjacent (002) lattice planes confirms that the $\mathrm{ZnO}$ nanopencils are referentially grown along the [001] direction. It can be easily observed that the crystal is well-oriented with no observable structural defects and thus, highly crystalline. These results are comparable to those obtained by earlier works [19-21].

\section{Conclusion}

A benign hydrothermal synthesis of $\mathrm{ZnO}$ nanoflower with pencil-like petals, at low temperature and under facile conditions has been reported. From the results of XRD, FESEM, TEM, HRTEM, and EDX techniques, it has been observed that the $\mathrm{ZnO}$ flowers with nanopencils-like petals are of high crystallinity with a diameter in range of 45-60 nm. This benign synthesis method can easily be extended for the synthesis of other nanostructures, especially to metal oxides. It would be helpful in reducing the adverse effects of nanotechnology on the environment which is already under a large stress.

Open Access This article is distributed under the terms of the Creative Commons Attribution License which permits any use, distribution, and reproduction in any medium, provided the original author(s) and the source are credited.

\section{References}

1. Lazoryak, B.I., Baryshnikova, O.V., Stefanovich, S.Y., Malakho, A.P., Morozov, V.A., Belik, A.A., Leonidov, I.A., Leonidova, O.N., Tendeloo, G.V.: Ferroelectric and ionic-conductive properties of nonlinear-optical vanadate, $\mathrm{Ca}_{9} \mathrm{Bi}\left(\mathrm{VO}_{4}\right)_{7}$. Chem. Mater. 15, 3003-3010 (2003)

2. Felix, M., Christina, C., Frank, C.: Biofunctionalization of fluorescent rare-earth-doped lanthanum phosphate colloidal nanoparticles. Angew. Chem. Int. Ed. 43, 5954-5957 (2004)

3. Tretyakov, Y.D. (ed.): Nanotechnologies. The alphabet for everyone. Fizmatlit, pp. 344-345 (2008)

4. Al-Harbi, L.M., El-Mossalamy, E.H., Arafa, H.M., Al-Owais, A., Shah, M.A.: Growth of $\mathrm{ZnO}$ nanorods and their optical properties. Mod. Appl. Sci. 5, 87-91 (2011)

5. Ebrahim, S., Khanlari, M.R., Durani, R.S.: Study of $\mathrm{ZnO}$ nanopencils and nanoneedles morphology synthesized on quartz substrate in ambient air and without catalyst. In:4th International Conference on Nanostructures (ICNS4). pp. 679-680 (2012)

6. Jiang, C.Y., Sun, X.W., Lo, G.Q., Kwong, D.L., Wang, J.X.: Improved dye sensitized solar cells with a $\mathrm{ZnO}$ nanoflower photoanode. Appl. Phys. Lett. 90, 263501 (2007)

7. Hsueh, T.J., Hsu, C.L.: Fabrication of gas sensing devices with $\mathrm{ZnO}$ nanostructures by the low temperature oxidation of zinc particles. Sens. Actuators B Chem. 131, 572-576 (2008)

8. Ge, C., Bai, Z., Ho, M., Zeng, D., Cai, S., Xi, C.: Preparation and gas sensing property of $\mathrm{ZnO}$ nanorod bundle thin films. Mater. Lett. 62, 2307-2310 (2008)

9. Kharisov, B.I.: A review for synthesis of nanoflowers. Recent Pat. Nanotechnol. 2, 190-200 (2008)

10. Moulani, A., Sediri, F.: Pencil-like zinc oxide micro/nano-scale structures: hydrothermal synthesis, optical and photocatalytic properties. Mater. Res. Bull. 48, 3723-3728 (2013)

11. Badgujar, P.S., Arbuj, S.S., Mali, J.M., Rane, S.B., Mulik, U.P.: A simple protocol for synthesis of pencil-like $\mathrm{ZnO}$ rods and their photocatalytic performance study. J. Nanoeng. Nanomanufacturing 4, 1-6 (2014)

12. Tan, L., Yu, X., Zhang, L., Wang, P.: Growth of waist ZnO twin rods through hydrothermal synthesis. J. Nanosci. Nanotechnol. 14, 3233-3238 (2014)

13. Baruah, S., Dutta, J.: Hydrothermal growth of $\mathrm{ZnO}$ nanostructures. Sci. Technol. Adv. Mater. 10, 013001 (2009)

14. Al-Hartomy, O.A., Shah, M.A.: Safe and simple approach to prepare hexagonal $\mathrm{ZnO}$ nanostructures in water. Int. Conf. Nanotechnol. Biosens. IPCBEE. 2, 139-142 (2011)

15. Shah, M.A., Al-Shahry, M.S., Asiri, A.M.: Simple approach for the synthesis of zinc oxide nanorods. Int. J. Nanoparticles 2, 66-73 (2009)

16. Sofi, A.H., Shah, M.A.: The study of structural and morphology features of indium oxide nanostructures. Mater. Res. Express 1, 015041 (2014)

17. Wang, C.X., Yang, G.W.: Thermodynamics of metastable phase nucleation at the nanoscale. Mater. Sci. Eng. R 49, 157-202 (2005)

18. Pol, V.G., Moreno, J.M.C., Thiyagarajan, P.: Facile synthesis of novel photoluminescent $\mathrm{ZnO}$ micro- and nanopencils. Langmuir 24, 13640 (2008)

19. Yu, J., Huang, B., Qin, X., Zhang, X., Wang, Z., Liu, H.: Hydrothermal synthesis and characterization of $\mathrm{ZnO}$ films with different nanostructures. Appl. Surf. Sci. 257, 5563-5565 (2011)

20. Wu, J.J., Liu, S.C.: Catalyst-free growth and characterization of ZnO nanorods. J. Phys. Chem. B 106, 9546-9551 (2002)

21. Suhaimi, S., Sakrani, S., Dorji, T., Ismail, A.K.: A catalyst-free growth of aluminum-doped $\mathrm{ZnO}$ nanorods by thermal evaporation. Nanoscale Res. Lett. 9, 256-265 (2014) 